\title{
Systemic Approach to Learning Paradigms and the Use of Social Media in Higher Education
}

\author{
$\underline{\text { doi:10.3991/ijet.v6iS1.1616 }}$ \\ Lauri Kurkela \\ Oulu University of Applied Sciences, Oulu, Finland
}

\begin{abstract}
The implementation of social media in learning, teaching and cooperation is an innovation process which has implications at many levels in networking universities. eLearning developers and educational designers need to be aware of social media related technological prospects to be able to determine how to benefit from new possibilities. They also need to be aware of related pedagogical possibilities, competences and attitudes among students, teachers and tutors. Soft System Methodology (SSM) has been applied to investigate the problem area more deeply. One can see three development challenges at each level: 1) paradigms and paradigm shifts, 2) teaching and learning competences and related culture, 3 ) infrastructure and technology related services and innovations. The Virtual Campus for Digital Students (ViCaDiS) Project is used to concretise some features of the systemic approach of SSM. As a result of the SSM analysis, one can find a useful framework to start analysing development challenges in the context of one university or universities working together.
\end{abstract}

Index Terms-Educational Technology, Organizational Learning, Social Implications of Technology, Social Media, Soft System Methodology.

\section{INTRODUCTION}

This paper focuses on the systemic understanding of the implementation process of social media in formal learning in the context of higher education (HE). The concept of social media is associated with web services known as Web 2.0, which open rich possibilities for the use of the Internet. Social media and related services are essential facilitators for learning, teaching and educational cooperation. The use of social media serves both informal and formal learning. In formal learning the use of social media can be structured and guided by educational institutions for example the learning process could be guided through various learning tasks. In practice informal and formal learning are often bound to each other in many ways [9].

Social media have begun to influence business and knowledge sharing practices in many organizations. Social media related competences are becoming more important for learners' vocational growth and life-long learning. Social media resources could allow us to conduct our core processes differently [8]. In higher education this means innovation processes with social media related technology transfer, revised cooperation, learning and teaching competences and related paradigm shifts. Social media resources may facilitate substantially better processes in higher education. Nevertheless, users can use appropriate information technology in unexpected ways - there can be unintended negative consequences involved. Any poten- tial change to our core processes should, therefore, be considered critically and carefully [8].

Social media are often associated with the concept of Community of Practice. The concept Community of Practice $(\mathrm{CoP})$ was introduced by Lave and Wenger $[13 ; 23$; 24] who claim that it is essential to CoPs that partners have $a$ shared domain of interest and shared goals which form the basis of cooperation. In CoPs they build relationships that enable them to learn from each other $[13 ; 24]$. Relationships in the context of higher education are specified partly by pedagogical settings and paradigms of formal learning and partly by students.

In the ViCaDiS (Virtual Campus for Digital Students) Project (2007-2009), six European countries and ten partners implemented social media and mobile features in the learning environments of partner universities. The basic ideas of the ViCaDiS Project are: 1) to facilitate international cooperation in learning by using social media and open source applications; 2) to facilitate a shift from Institutional Learning Environments (ILE) towards Personal Learning Environments (PLE), and 3) to create an attractive environment for all students in all states of the European Union. The ViCaDiS Project conducted several questionnaires using the ZEF Evaluation Engine (see http://kysy.oamk.fi/zef/docs/zef-method-en.pdf,

http://www.zefsolutions.com). Two of the questionnaires focused on digital student characteristics, the potential of mobile technologies for eLearning and the potential for educational uses of social media $[17 ; 18 ; 21]$. Two further pre- and post-piloting questionnaires were focused on piloting the ViCaDiS Campus to update the digital student profiles. Some results of these questionnaires are presented in this paper and the social media implications for higher education are discussed.

The implementation of social media in learning, teaching and educational cooperation is an innovation process that has implications at all levels within the partner universities. Innovations are new, renewed or enhanced processes, services, pedagogical improvements, research \& development competencies, learning, practice of work, strategies, etc. The innovation process consists of 1) discovery of ideas, 2) development of ideas and 3) implementation of ideas.

Soft System Methodology (SSM) [4; 5; 6] has been applied to understand the problem area more deeply. The World View (Weltanschaunng) selected in the SSM analysis is described as follows: There are three major development challenges at each level: 1) paradigms and paradigm shifts, 2) teaching and learning competences and related culture, 3) infrastructure and technology related services and innovations. 
As a result of the SSM analysis presented in this paper, one can find a useful framework to start analysing development challenges in the context of one university or networking universities working together.

\section{LEARNING PARADIGMS AND SOFT SYSTEM METHODOLOGY}

SSM has been used successful in cases where so-called hard system methodologies have failed $[4 ; 5 ; 6]$. Through SSM we can find several levels of interrelated learning paradigms from individual learning tasks to university level cooperation. Paradigms have visible and invisible features. The visible formal side of a paradigm consists of processes, roles, tools, etc. The invisible informal side (culture) of a paradigm consists of customs, values, taboos, stereotypes, traditions, language behaviours, etc. [14]. Paradigms and paradigm shifts at each level are important for successful implementation of social media. Paradigm refers to the functional model(s) which guide a system or its subsystems. A paradigm shift must be technically possible and culturally acceptable. Paradigm shifts include both formal and informal features $[4 ; 5 ; 6]$. Usually the desired cultural change is more demanding than the technological one [14]. Innovation processes consist of paradigm shifts, restructuring of cooperative entities and development and implementation of resources. At each level a successful paradigm shift requires the existence of four elements: 1) pressure for change, 2) a clear shared vision, 3) capacity for change, and 4) actionable first steps [7]. If any of these elements is missing, the paradigm shift will fail. Paradigms affect what kind of learning (and social media related) resources are needed and learning resources affect what kind of paradigms can be used or developed.

eLearning and Blended Learning are seen here broadly as synonyms. They are involved in the flexible use of social media related services and resources in learning, teaching, cooperation and working related situations. They are involved in the innovations of pedagogy or technology enhanced learning.

The concept eLearning 2.0 (introduced by Stephen Downes in 2005) highlights these technological and methodological changes. In Wikipedia, eLearning 2.0 is defined as "a second phase of Web 2.0 and emerging trends in eLearning. It can include such features as e-Learning where students create content, collaborate with peers to form a learning network with distribution of content creation and responsibilities, e-Learning that takes advantages of many sources of content aggregated together into learning and e-Learning that utilizes various tools including online references, courseware, knowledge management, collaboration and search. The term suggests that the traditional model of eLearning as a type of content, produced by publishers, organized and structured into courses, and consumed by students, is reversed; so a that content is used rather than read and is more likely to be produced by students than courseware authors" [3].

Social media related learning resources can have pedagogical, functional and content-related features (see Fig. 1).

A characteristic of social media is that the role of learners as content creators and networking actors is strong. The paradigm shift in the learners' role (as part of the paradigm shift of the institutional culture) also requires

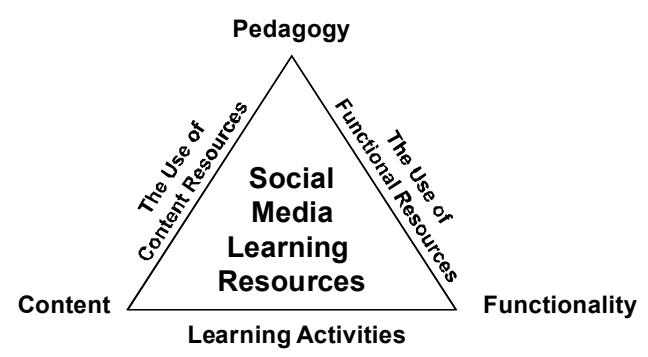

Figure 1. Properties of Social Media Learning Resources

changes in the pedagogical settings and pedagogical paradigms. Enhanced functionalities (essential to social media) are required to respond to the needs of learners, teachers and tutors.

Paradigm shifts are organizational development tools used to improve the quality and purposefulness of higher education. Through the development of pedagogical, functional and content-related resources and revised paradigms an organization aims to increase synergy.

Synergy is related to the benefits and added value gained in fulfilling the needs of different actors, systems or sub-systems in the design of paradigms, resources and value chains. Synergy enablers and synergy disablers are features which facilitate or prevent the growth of synergy. Synergy is growing if the (sub)system produces added value for its environment (effectiveness), if the added value is produced using purposeful means (efficacy), or if the added value is produced using minimal resources (efficiency) $[4 ; 5 ; 6]$.

Cannon-Leary and Fontainha [2] describe synergy enablers and disablers as benefits, barriers and critical success factors (CSFs) related to CoPs and learning communities as a table (Table 1).

TABLE I.

BENEFITS, BARRIERS AND CSFS [2]

\begin{tabular}{|c|c|c|}
\hline Benefits & Barriers & CSFs \\
\hline $\begin{array}{l}\text { Enhanced learn- } \\
\text { ing environments } \\
\text { Synergies cre- } \\
\text { ated } \\
\text { Capabilities } \\
\text { extended to } \\
\text { higher level } \\
\text { Knowledge } \\
\text { sharing \& learn- } \\
\text { ing } \\
\text { Gaining insights } \\
\text { from other } \\
\text { Deepening of } \\
\text { knowledge, } \\
\text { innovation \& } \\
\text { expertise } \\
\text { Cyclical, fluid } \\
\text { knowledge de- } \\
\text { velopment } \\
\text { Feeling of con- } \\
\text { nection } \\
\text { Ongoing interac- } \\
\text { tions } \\
\text { Assimilation into } \\
\text { sociocultural } \\
\text { practices } \\
\text { Neo- } \\
\text { apprenticeship } \\
\text { style of learning } \\
\text { Practice-based } \\
\text { usage }\end{array}$ & $\begin{array}{l}\text { Perpetuation vs. } \\
\text { change and diversity } \\
\text { Disciplinary differ- } \\
\text { ences } \\
\text { Culture of inde- } \\
\text { pendence } \\
\text { Tacit knowledge } \\
\text { Specialist language } \\
\text { Collegiality, strong } \\
\text { physical community } \\
\text { Shifting membership } \\
\text { Creating and main- } \\
\text { taining information } \\
\text { flow } \\
\text { No F2F to break the } \\
\text { ice } \\
\text { Read-only partici- } \\
\text { pants (lurkers) } \\
\text { Hidden identities, } \\
\text { adopted personas } \\
\text { Lack of trust - per- } \\
\text { sonal and institu- } \\
\text { tional } \\
\text { Selectivity in ICT } \\
\text { use } \\
\text { No body language, } \\
\text { misinterpretations } \\
\text { Task-based usage }\end{array}$ & $\begin{array}{l}\text { Good use of Internet stan- } \\
\text { dard technologies } \\
\text { Technological provision } \\
\text { ICT skills } \\
\text { Institutional acceptance of } \\
\text { ICT as communication } \\
\text { media } \\
\text { Good communications } \\
\text { Trust } \\
\text { Common values } \\
\text { Shared understanding } \\
\text { Prior knowledge of mem- } \\
\text { bership } \\
\text { Sense of belonging } \\
\text { Cultural awareness } \\
\text { Sense of purpose } \\
\text { Sensitivity in monitoring, } \\
\text { regulating, facilitating } \\
\text { Netiquette } \\
\text { User-friendly language } \\
\text { Time to build up the CoP } \\
\text { Regular interaction } \\
\text { Good coordination to } \\
\text { achieve regular but varied } \\
\text { communication } \\
\text { Material resources or } \\
\text { sponsorship to bolster and } \\
\text { build up the community }\end{array}$ \\
\hline
\end{tabular}


The concept of Interoperable Competence (IC) serves our systemic understanding of the target organization and its synergy processes. Interoperable competence guides our attention to: interoperability between actors (persons, organizational levels, organizational entities, services, networks, levels of the society), ability to serve other actors (on the same or different level), and ability to utilise services produced by other actors (on the same or different level). Interoperability can be horizontal or vertical by nature depending on whether the cooperation is related to resources and services at the same level or at different levels. Interoperable competence includes the views of different organizational levels, interest groups and individual actors [15].

Interoperability is also related to selected eLearning tools and organizational working models. According to Conella and Pantò [3], eLearning 2.0 is the most effective didactic architecture for companies where intellectual capital and the competences involved in updating and managing one's own knowledge are more important than the production of goods and services.

\section{The Multi-Level InNOVATION Process}

The social media implementation problem area is described in this paper as a multileveled, complex system. A complex system is something more than the sum of its components (subsystems). Components affect each other by paradigms, information exchange and resources. A complex system also affects its subsystems and - when it is changed - the subsystems are changed as well. By purposeful paradigm shifts and development of resources on a subsystem level the whole system can be guided in the desired direction. The World View selected by this SMM identifies three interrelated development challenges on each level: 1) paradigms and paradigm shifts, 2) teaching and learning competences and related culture, 3) infrastructure and technology related services and innovations (see Fig. 2).

eLearning infrastructure and technology are bound to prospects that facilitate learning related CoPs through innovative information technology. Teaching and learning competences and related culture guide the learning process of CoPs in the context of formal learning. Paradigms and paradigm shifts bind the learning process and outcomes to formal higher education.

The interacting and interrelated levels in Fig. 3 (from top to bottom) are: 1) Level of University and Networking Universities, 2) Level of Curriculums and Courses, 3) Level of Learning Tasks, 4) Level of Media elements and Related Metadata. All the development challenges are present on all the levels:

On the Level of University and Networking Universities, the following development challenges were identified: Educational technology transfer related to development of learning environments and learning resources Teaching and learning competence and related culture Paradigms and paradigm shifts.

On the Level of Curriculums and Courses, the following development challenges were identified: Selected learning environments and learning resources - Curriculum design and learning goals - Curriculum and course descriptions.

On the Level of Learning Tasks, the following development challenges were identified: Learning environ-

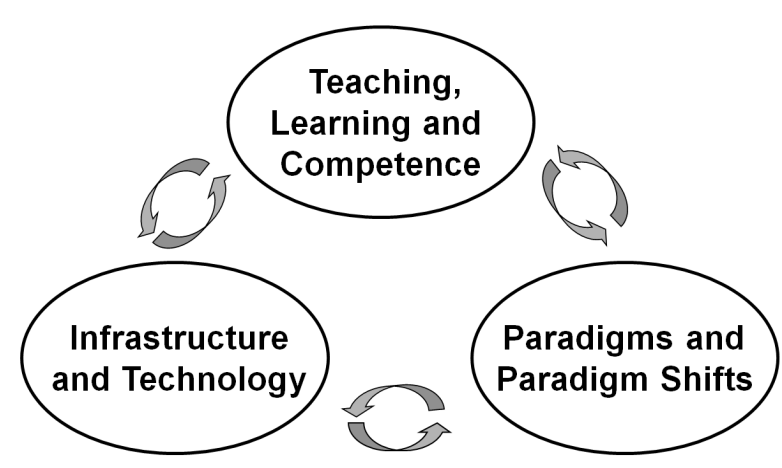

Figure 2. Three development challenges

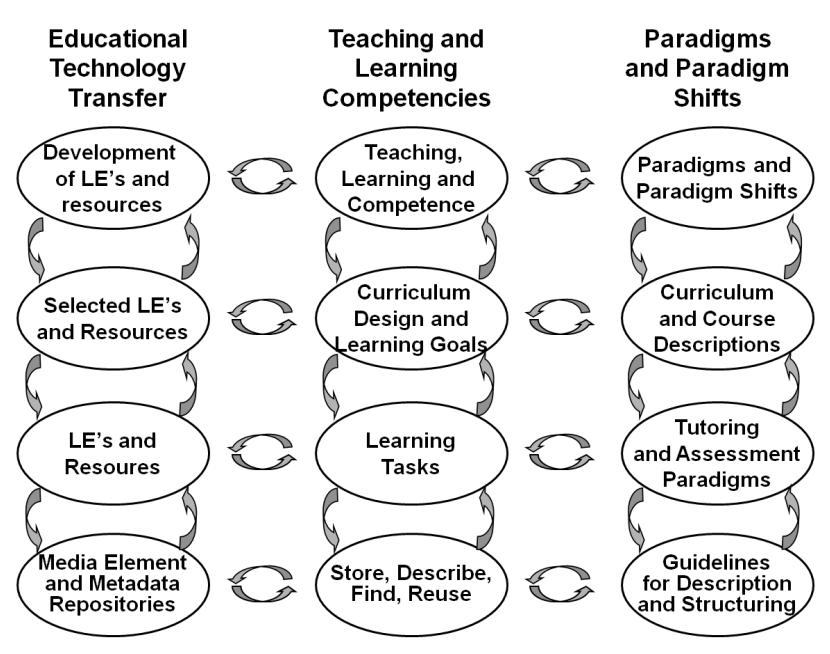

Figure 3. Summary of interacting levels

ments and learning resources - Learning tasks - Tutoring and assessment paradigms.

On the Level of Media Elements and Metadata, the following development challenges were identified: Repositories for media elements and metadata - How-to store, describe, search and reuse media elements - Guidelines for description and structuring

\section{TECHNOLOGICAL PROSPECTS}

Awareness of social media related technological prospects is one of the success factors in the social media innovation process.

On the university level technological prospects are bound to (or focused on) educational technology transfer related to the development of learning environments and learning resources.

On the Curriculum and Course Level awareness about technological prospects is focused on 1) the social media services supported by the university or by networking universities and 2) services with easy access offered outside the university. In the ViCaDiS Project the ViCaDiS Campus was related to the first and widely used services like Skype are related to the second.

On the Level of Learning Tasks awareness about technological prospects is focused 1) on technologies selected by educational designers, teachers and tutors and 2) on technologies freely selectable by students or groups of students. In both cases services are selected from services supported by the university or from freely available services outside the university. 
On the Level of Media Elements and Metadata awareness about technological prospects is focused on how social media elements are created, structured, found, reused and described with metadata. On a proper level of granularity media elements are meaningful learning objects where social media content is associated with functional and pedagogical features to serve the needs of learners and teachers. In the ViCaDiS Campus some social media activities (like Wikis, Forums, etc.) and usage related statistics serve these needs.

\section{Pedagogical Prospects}

Awareness of teaching and learning competencies and related cultural aspects are the second success factor.

On the Level of University and Networking Universities this is related to 1) educational strategies and practices related to educational cooperation (networking entities), 2) utilisation of innovative information technology, and 3) pedagogical and social media related competences. In the ViCaDiS Project, key features on this level are social networking and international cooperation.

On the Curriculum and Course Level, awareness is related to pedagogical paradigms, teaching and learning competences and practices. The social media innovation process requires development activities and paradigm shifts with formal and informal (cultural) features.

On the Level of Learning Tasks pedagogical prospects are related to 1) pedagogical culture and competencies of teachers and tutors, 2) learning competences and learning culture of students, 3) learning tasks which facilitate the use of social media and 4) learning tasks which facilitate different paths for learning. New HE students have to adapt their learning activities and skills to the existing institutional learning and teaching culture. In the ViCaDiS Project, we had several piloting courses or communities of practice (CoPs) where learning tasks were based on the use of social media and where students were able to select the learning tasks and social media services which best supported their learning activities.

On the Level of Media Elements and Metadata pedagogical prospects are related to what kind of competencies are needed in the educational use of social media and what kind of information social media information systems gather, store and deliver automatically to serve the needs of learners, teachers and tutors. The ViCaDiS Campus is based on Moodle, which takes care of information gathered from user activities.

\section{PARADIGMS AND PARADIGM SHIFT RELATED PROSPECTS}

Paradigms and paradigm shifts are the third success factor. Paradigms have formal and informal features. Most of the informal features are related to pedagogical prospects. In our SSM analysis, paradigms and paradigm shifts are mostly related to formal features. In other words, paradigms and paradigms shifts bind the teaching and learning activities to serve formal education in higher education.

On the Level of University and Networking Universities, paradigms and paradigm shifts are related to 1) how universities are networking in their formal education in practice, 2) what kind of strategies and agreements are used to guide this practice, 3) what kind of paradigm shifts are possible (technically and culturally) to facilitate inter- university cooperation based on the use of social networking.

On the Level of Curriculums and Courses, formal learning related prospects are related to 1) how competence and learning activities are bound to formal degrees, 2) how personalisation and personal learning environments are facilitated in paradigms, 3) how learning in informal learning contexts is acknowledged in formal education, and 4) how curriculum and course descriptions guide and document learning activities based on the use of social media.

On the Level of Media Elements and Metadata, formal paradigms are related to instructions on how to deal with social media and related metadata to serve teaching and learning activities.

\section{THE VICADIS PROJECT}

In this section the SSM Analysis is illustrated with some selected examples from the ViCaDiS Project.

The Level of University and Networking Universities: The ViCaDiS Campus is an example of educational technology transfer. On this level, ViCaDiS investigated the problem area by evaluating mobile technology and social media related prospects $[16 ; 17 ; 18]$. Relevant mobile technologies identified were: Short Message Service (SMS), Multimedia Messaging Service (MMS), Wireless Application Protocol (WAP 2.0), Digital Rights Management (DRM), Push to talk over cellular (PoC), Voice over Internet Protocol (VoIP), Near Field Communication (NFC), Global Positioning System (GPS) and Assisted Global Positioning System (AGPS). The use of the ZEF Evaluation Engine $[1 ; 25]$ helped us to figure out what technologies should be implemented first [18]. The greatest potential was found in VoIP - audio and video communication and conferences with mobile devices. The possibility to access services with computers and mobile devices (dual-device-option) was also evaluated highly. Other technologies with great potential were: WAP $2.0-$ Secure login to web pages, learning environments and social web services, web browsing with mobile devices, web based calendar and calendar activities, timed messages from calendar activities, $\mathrm{PoC}$ - immediate sharing of documents, and SMS - rich content download services. From an eLearning quality perspective, we should start the implementation process from these technologies [20].

The most important finding from the 1st questionnaire came when the answers were grouped by roles. Teachers with eLearning experience $(\mathrm{N}=71)$ evaluated WAP 2.0 potential much higher than IT-specialists $(\mathrm{N}=37)$. See Fig. 4 which is in the normalised (z-scored) form.

Figure 4 shows WAP 2.0 related results from Teachers with eLearning Experience (upper part of the Fig. 4) and IT Specialists (lower part of the Fig. 4) in z-scored form. The Potential for eLearning and Probability to be Used were evaluated from the following viewpoints: 1) Web browsing with Mobile Devices; 2) Secure Login to Web Pages, Learning Environments and Social Web Services; 3) Web Based Calendar and Calendar Activities; 4) RSS Feeds from Calendar Activities; 5) Timed Messages from Calendar Activities; 6) RSS-feed for WAP 2.0 Services [17]. We could say that the interoperable competence between teachers with eLearning experience and IT specialists should be revised. Otherwise higher education will 


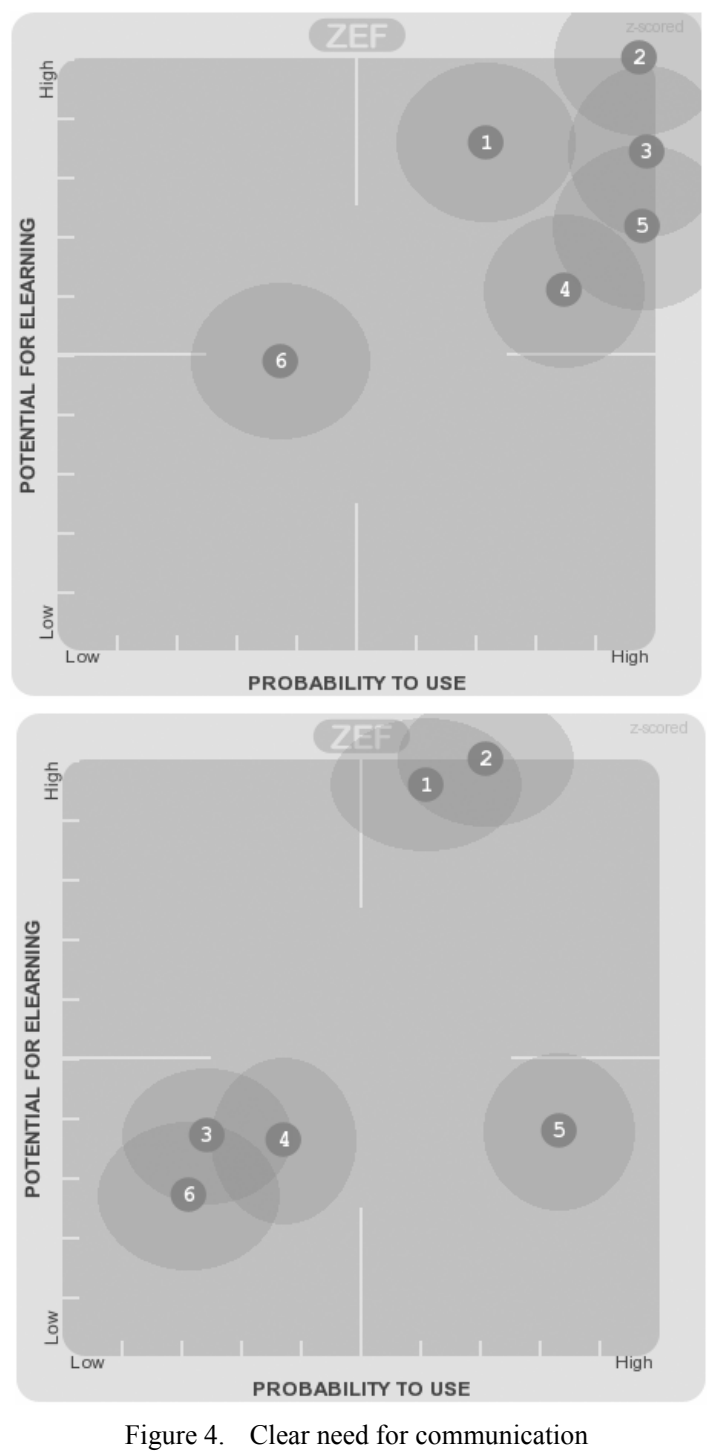

not be able to benefit fully from the possibilities of social media [11].

According to the first questionnaire [17] the first implementation steps in mobile learning technology should concentrate on questions that have achieved top scores in the top-right quarter of the normalised (z-scored) diagrams: VoIP - Voice over Internet Protocol: Audio and Video Communication and Conferences with Mobile Devices. WAP 2.0 - Wireless Application Protocol: Secure Login to Web Pages; Learning Environments and Social Web Services; Web Browsing with Mobile Services; Web Based Calendar and Calendar Activities; Timed Messages from Calendar Activities. PoC - Push to Talk over Cellular: Immediate Sharing of Documents. MMS - Multimedia Messaging Service: Dual Device Option - Mobile Devices and/or email. SMS - Short Message Service: Rich Content Download Services.

One of the most important challenges on this level is how social media and related CoPs can be used to serve formal education related needs of students from networking universities. ViCaDiS Campus facilitates social media oriented cooperation by providing interest areas for $\mathrm{CoPs}$ and learning environments for cooperation courses. However, social media related solutions can only facilitate
CoPs; they do not guarantee successful cooperation in the context of formal learning.

The Level of Curriculums and Courses: In the ViCaDiS Project the most challenging paradigm shift on this level was the shift from Institutional learning environments towards Personal learning environments. This is an excellent example of interoperability from an SSM point of view: If we change one subsystem (e.g. Shift towards PLEs in the curriculum and course level paradigms), the whole system has to adapt itself to this change. We have to adapt all the other subsystems on the same level and interrelated subsystems on levels above or under the level where we originally changed the first subsystem.

Social media related competences (by students and teachers) can be either synergy enablers or synergy disablers. Educational designers, teachers and tutors need competencies and experiences from the use of social media services available in the $\mathrm{ViCaDiS}$ Campus and also services available outside the Campus. At the moment the ViCaDiS Campus includes the following activities: Assignments (Advanced uploading of files, Online text, Upload a single file, Offline activity), Chat, Choice, Database, Flashcard trainer, Forum, Glossary, Lesson, Media, Mobile Learning Object, Mobile-Tag, OU Blog, Quiz, SCORM/AICC, Survey, Video aula, Wiki and Workshop. This is simply too much for a teacher who is a novice in eLearning and Moodle. In ViCaDiS we tried to describe and share our experiences by describing pedagogical settings and pedagogical patterns related to the different use cases of the campus in the ViCaDiS Set of Guidelines [22; $10]$.

In the Pre-piloting questionnaire [16] we had 151 answers: 280 invitations, $169(60.4 \%)$ had started to answer and $151(53.9 \%)$ had answered all the questions; answers from 160 students and 7 teachers/tutors, 67 female and 99 male; $41.6 \%$ had intermediate knowledge of the English language; $50.3 \%$ had intermediate ICT skills.

In Fig. 5, Social media and tools related results are presented on upper part of the figure in absolute and on lower part of the figure in $\mathrm{z}$-scored forms.

Number codes for social media and tools in Fig. 5 are: 1 Blogs, 2 Wikis, 3 Podcasting, 4 Forums, 5 Instant messaging, 6 Audio/video conferences, 7 emails, 8 RSS feeds, 9 Social bookmarking, 10 Shared web based calendar services, 11 sharing of learning materials produced by teachers and students (Pre-piloting Questionnaire, Preliminary Results).

On the top-right corner of the z-scored diagram (lower part of Fig. 5), one can see where the greatest potential is at the beginning. It's safe to start with familiar social media tools. On the bottom half of the lower part of Fig. 5 one can see where better competence and support is needed. And on the bottom-left corner one can identify features (Social bookmarking, Podcasting, RSS feeds, Shared web based calendar services, Blogs and Wikis) where low competence levels have probably prevented recognition of potential for learning. If these competencies are revised, we should re-evaluate their potential for learning $[12 ; 15]$.

We have so few answers from teachers, that we can not yet draw any meaningful conclusions concerning teachers and tutors. 


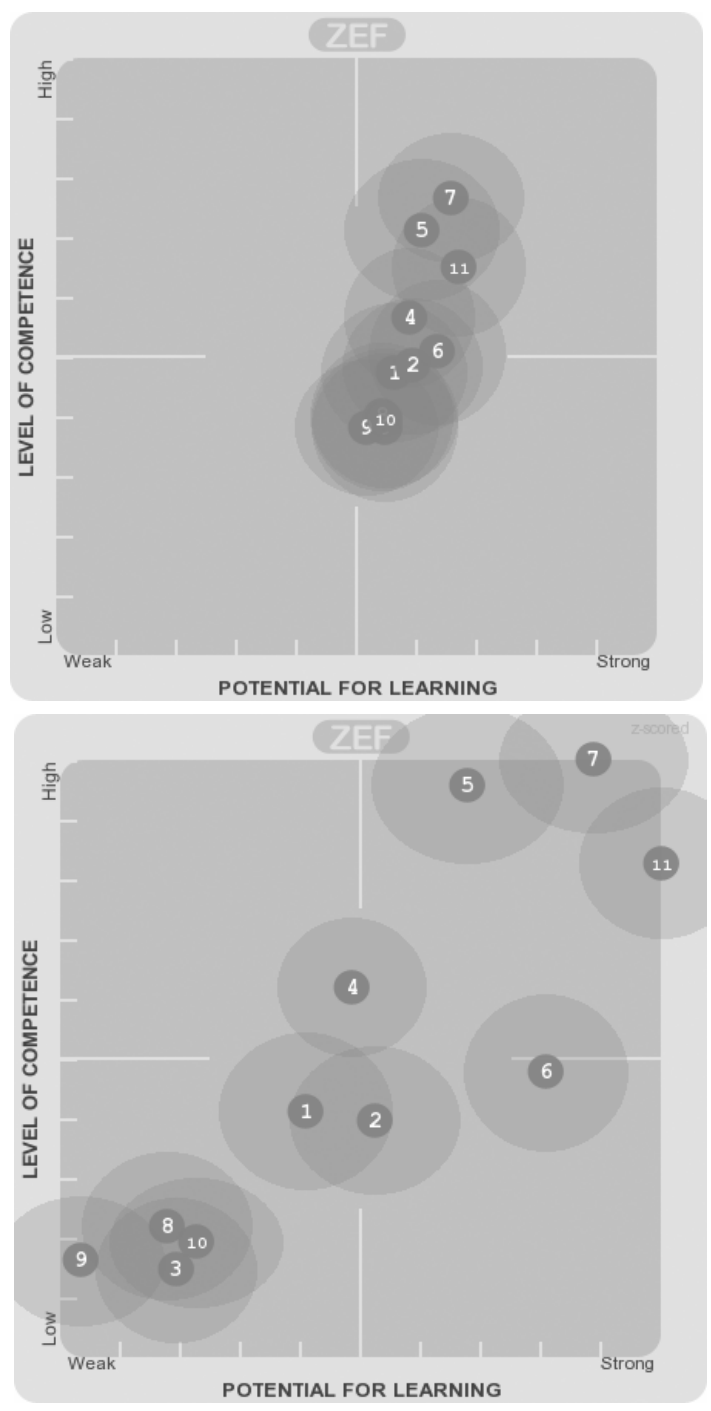

Figure 5. Social media and tools (All)

The Level of Learning Tasks: Educational use of social media demands changes in the teaching and learning culture and paradigms. It demands awareness and competencies related to available social media services. Learning tasks can benefit from CoPs that are established to serve formal or informal learning. Self-directedness of learners, their awareness of learning goals and their own learning process as a part of their vocational growth are important enablers for successful educational use of social media.

The Level of Media Elements and Metadata: In the ViCaDiS Campus, several services track the use of social media activities. They are very important for educational designers, teachers, tutors and students who want to improve the quality of social media related eLearning.

\section{CONCLUSIONS}

A systemic approach to learning paradigms and the use of social media has increased our understanding of this complex problem area. The problem area was analysed through SSM, which led to a multilevel system with three development challenges and subsystems on each level. The development challenges are: 1) Social media as a part of educational technology transfer, 2) Social media teaching and learning competencies and related culture and 3) Learning paradigms and paradigm shifts which bind the
TABLE II.

LIST OF ACRONYMS

\begin{tabular}{|l|l|}
\hline \multicolumn{1}{|c|}{ Acronym } & \multicolumn{1}{c|}{ Description } \\
\hline AGPS & Assisted Global Positioning System \\
\hline CoP & Community of Practice \\
\hline CSF & Critical Success Factor \\
\hline DRM & Digital Rights Management \\
\hline F2F & Face-to-Face \\
\hline GPS & Global Positioning System \\
\hline HE & Higher Education \\
\hline IC & Interoperable Competence \\
\hline ILE & Institutional Learning Environment \\
\hline MMS & Multimedia Message Service \\
\hline NFC & Near Field Communication \\
\hline PLE & Personal Learning Environment \\
\hline PoC & Push to talk over cellular Communication \\
\hline RSS Feed & $\begin{array}{l}\text { Really Simple Syndication which provides a } \\
\text { quick listing of updated website information }\end{array}$ \\
\hline SMS & Short Message Service \\
\hline SSM & Soft System Methodology \\
\hline ViCaDiS & Virtual Campus for Digital Students \\
\hline VoIP & Voice over Internet Protocol \\
\hline WAP & Wireless Application Protocol \\
\hline ZEF & Z-scored Electronic Feedback \\
\hline
\end{tabular}

learning activities and learning outcomes to formal learning. In this kind of a complex system, a change in one subsystem affects both other subsystems and the behaviour of the whole system. When a higher education institution develops one of its subsystems, the system changes and there are also changes in various synergy enablers and synergy disablers. This leads to a new iteration in the use of SSM. A successful paradigm shift requires the existence of four elements: 1) pressure for change, 2) a clear shared vision, 3) capacity for change and 4) actionable first steps [5]. If any of these elements is missing, the paradigm shift will fail. Paradigms affect what kind of learning (and social media related) resources are needed and learning resources affect what kind of paradigms can be used or developed.

The ViCaDiS project was used as an example to clarify some features of the problem area. Pressure for change comes from the development of technology and changes in the surrounding society and work life. The SSM analysis started in this paper increases our shared understanding of the problem area.

The use of SSM and presented multilevel model is also a practical tool to analyse and understand the development challenges in other universities and cooperation networks. It can be used together with the table from Cannon-Leary and Fontainha [2] as a starting point for university specific development activities.

\section{REFERENCES}

[1] Anttila, J., 2007. ZEF related blog notation by Juhani Anttila http://qiblog.blogspot.com/2007 0601 archive.html, [Accessed 22 November 2009].

[2] Cannon-Leary, P. \& Fontainha, E. Communities of Practice and virtual learning communities: benefits, barriers and success factors. eLearning Papers, No. 5, September 2007. http://www.elearningpapers.eu [Accessed 28 June 2010].

[3] Conella, L. \& Pantò, E. Didactic architectures and organization models: a process of mutual adaptation. eLearning Papers No. 9, July 2008. http://www.elearningpapers.eu [Accessed 28 June 2010].

[4] Checkland, P. \& Holwell, S., 1998. Information, Systems and Information Systems: making sense of the field. John Wiley \& Sons. 
SPECIAL FOCUS PAPER

\section{Systemic Approach to LeARning PARAdigMS AND the Use of SOCIAL MEdia In Higher EdUCATION}

[5] Checkland, P. \& Scholes, J. 1999. Soft Systems Methodology in Action. John Wiley \& Sons.

[6] Checkland, P. 1999. Systems Thinking, Systems Practice. John Wiley \& Sons.

[7] de Woot, P. 1996. Managing Change at University, Journal of the Association of European universities - CRE-action No. 109.

[8] Kane, G. \& Fischman, R., The Shoemaker's Children: Using Wikis for Information Systems Teaching, Research, and Publication. MIS Quarterly Vol. 33 No. 1, pp. 1-17, March 2009.

[9] Kiviniemi, K. \& Kurkela, L. The Role of Social Media in Informal and Formal Learning, presentation and paper in the 10th international conference on VIRTUAL UNIVERSITY in Bratislava, 2009.

[10] Kurkela L. The Potential of Design Patterns for Vocational Teacher Education in Finland, Netties 2006.

[11] Kurkela, L. Mobile Learning Implications in the ViCaDiS Project. Presentation and paper in the IADIS International Conference on Cognition and Exploratory Learning in Digital Age - CELDA, 2009.

[12] Kurkela, L., Fähnrich, B. \& Kocsis-Baan, M. Piloting of a Virtual Campus for Interuniversity Cooperation. Presentation and paper in the IADIS International Conference on Cognition and Exploratory Learning in the Digital Age - CELDA, 2009.

[13] Lave, J. \& Wenger, E. Situated learning: legitimate peripheral participation. Cambridge University Press, Cambridge, 1991.

[14] Neus, A. \& Scherf, P. Opening minds: Cultural change with the introduction of open-source collaboration methods. IBM SYSTEMS Journal, Vol. 44, No. 2, 2005.

[15] Pekonen, E. A summary of the concept of Interoperable Competence in a workshop (12/4/2002). Workshop participants: Erkki Pekonen, Anita Rubin, Jarmo Toiskallio and Lauri Kurkela.

[16] Pre-piloting Questionnaire in the ViCaDiS Project.

[17] Questionnaire 1. Support site for questionnaire 1: http://www.oamk.fi/ laurik/mLearning/ and Summary: http://mobilevicadis.wordpress.com/11-summary/ [Accessed 22 November 2009].

[18] Questionnaire 2. Support site and results for questionnaire 2: http://mtools.wordpress.com// [Accessed 22 November 2009.]

[19] Results 1. Results by groups in the 1st Questionnaire http://www.oamk.fi/ laurik/mLearning/results/SubGroup/Results \%20by\%20Groups.html [Accessed 22 November 2009].

[20] [20] Rutkauskiené, D. Kurkela, L. \& Ambraziené, D. Challenges posed to e-learning quality by mobile technologies. The Quality of Higher Education, 2008: 5, s. 201-219.

[21] Vasiu, V., Andone, D. \& Robu, N., Ideas and Concepts of Virtual Campus for Digital Students. Presentation and full paper in the IADIS International Conference on Cognition and Exploratory Learning in Digital Age - CELDA, 2009.

[22] ViCaDiS Set of Guidelines. http://www.vicadis.net/set/ [Accessed 28 July 2010].

[23] Wenger, E. Communities of practice: a brief introduction. http://www.ewenger.com/theory/index.htm, 2005 [Accessed 22 November 2009].

[24] Wenger, E. Communities of practice. Learning, meaning, and identity. Cambridge University Press, Cambridge, 1998.

[25] ZEF Solution, Products and Services http://eduzef.com/ en/solutions.php [Accessed 22 November 2009].

\section{AUTHOR}

L. Kurkela is with the School of Engineering, Oulu University of Applied Sciences, Kotkantie 1, 90250 Oulu, Finland (e-mail: lauri.kurkela@oamk.fi).

This article was modified from a presentation and paper at The $10^{\text {th }} \mathrm{In}$ ternational Virtual University Conference, in 10-11 December 2009, Bratislava, Slovak Republic.

Received, March $25^{\text {th }}, 2010$. Published as resubmitted by the author April $20^{\text {th }}, 2011$. 